\title{
O poder de polícia e a administração da Justiça: Estado e partido na Alemanha nazista e na Itália fascista
}

DOI: 10.15175/1984-2503-202113303

\author{
João Fábio Bertonha*
}

\begin{abstract}
Resumo
O objetivo desse artigo é discutir as diferenças e igualdades entre os sistemas policiais e judiciários construídos nas ditaduras fascistas (Itália e Alemanha) e suas implicações no colapso do fascismo em 1943 e na sobrevivência do nazismo até 1945. Também será discutida a cultura policial e judicial criada nesses regimes e a sua sobrevivência no período posterior, com o consequente déficit democrático. Como pano de fundo, será discutida a relação entre policiais, juízes e milicianos dentro dos regimes fascista italiano e nazista alemão e o tema mais amplo da relação entre Estado e partido nesses regimes. Como "casos de controle", serão abordados igualmente os exemplos da Espanha, do Brasil e do Japão.
\end{abstract}

Palavras-chave: Organizzazione per la Vigilanza e la Repressione dell'Antifascismo (OVRA); Schutzstaffel (SS); polícia; sistema judicial.

El poder de la policía y la administración de la justicia: Estado y partido en la Alemania nazi y en la Italia fascista

\section{Resumen}

El objetivo de este artículo es discutir las diferencias y semejanzas entre los sistemas policiales y judiciales construidos en las dictaduras fascistas (Italia y Alemania) y sus implicaciones en el colapso del fascismo en 1943 y en la supervivencia del nazismo hasta 1945. También se debatirá sobre la cultura policial y judicial creada en esos regímenes y su supervivencia en el período posterior, con el consecuente déficit democrático. Como telón de fondo, se analizará la relación entre la policía, los jueces y los milicianos dentro de los regímenes fascista italiano y nazi alemán, y el tema más amplio de la relación entre el Estado y el partido en estos regímenes. Como «casos de control», se abordarán igualmente los ejemplos de España, Brasil y Japón.

Palabras clave: Organizzazione per la Vigilanza e la Repressione dell'Antifascismo (OVRA); Schutzstaffel (SS); policía; sistema judicial.

Police power and the administration of justice: State and party in Nazi Germany and Fascist Italy

\section{Abstract}

The aim of this article is to discuss the differences and similarities between the police and legal systems shaped during the Fascist dictatorships of Italy and Germany and their implications on the collapse of Fascism in 1943

\footnotetext{
* Doutor em História pela Universidade Estadual de Campinas. Professor de História (graduação e pósgraduação) na Universidade Estadual de Maringá. Professor associado (externo) do Instituto de Politica y Gobernanza da Universidad Carlos III de Madrid. E-mail: fabiobertonha@hotmail.com.

(9) http://lattes.cnpq.br/9741185590842490. (ㄴ) https://orcid.org/0000-0002-5194-5632
} 
and the survival of Naziism until 1945. The article also discusses the police and legal culture created under these regimes and its survival in the later period, with the consequent democratic deficit. The backdrop to this is a discussion on the relationship between police officers, judges, and militiamen within the regimes of Italian Fascism and Nazi Germany and the broader subject of the relationship between State and party in these regimes. As "case-control studies", the examples of Spain, Brazil, and Japan will also be discussed.

Kewords: Organizzazione per la Vigilanza e la Repressione dell' Antifascismo (OVRA); Schutzstaffel (SS); police; legal system.

Le pouvoir de police et l'administration de la Justice : État et parti dans l'Allemagne nazie et l'Italie fasciste

\section{Résumé}

L'objectif de cet article est de mettre en perspective les différences et les similitudes entre les systèmes policiers et judiciaires mis en place par les dictatures fascistes (Italie et Allemagne) et leurs implications dans la chute du fascisme en1943 et la survie du nazisme jusqu'en 1945. Sera également abordée la culture policière et judiciaire créée par ces régimes et leur survie lors de la période ultérieure, avec le déficit démocratique que cela implique. En toile de fond, nous analyserons la relation entre policiers, juges et miliciens au sein des régimes fasciste italien et nazi allemand, ainsi que la question plus large du rapport entre État et parti dans les régimes en question. Comme " cas contrôle », nous aborderons également les exemples de l'Espagne, du Brésil et du Japon.

Mots-clés : Organizzazione per la Vigilanza e la Repressione dell' Antifascismo (OVRA); Schutzstaffel (SS) ; police ; système judiciaire.

\section{警察权力与司法管理：纳粹德国和法西斯意大利的国家机器与政党之间的关系}

\section{摘要}

本文的目的是讨论在法西斯独裁统治下（意大利和德国）建立的警察和司法系统，它们之间的异同，以及它们 对 1943 年意大利法西斯主义崩溃和1945年德国纳粹主义的灭亡的影响。本文还将讨论警察文化和司法文化在 这些政权中的创建及其在随后时期的生存，以及随之而来的民主赤字。作为背景，将讨论意大利法西斯和德国 纳粹政权内警察、法官和民兵之间的关系，以及这些政权中国家机器与政党之间关系。作为“参照案例”，本 文还列举了西班牙、巴西和日本的一些例子。

关键词：希特勒；墨索里尼；意大利监视和镇压反法西斯组织(OVRA)；德国党卫军；警察；司法系统

\section{Introdução}

Uma característica peculiar dos Estados fascistas é que eles mantinham, dentro da sua estrutura de poder, partidos únicos que deviam controlar e gerir hierarquicamente suas sociedades. Tais partidos seriam as bases para um projeto de futuro totalitário no qual as antigas estruturas estatais seriam eliminadas e uma nova elite assumiria 0 controle da sociedade.

Na prática, a concepção totalmente hierarquizada e totalitária de sociedade não se concretizou, em boa medida pela própria resistência dos ditadores em criar estruturas que 
poderiam, a princípio, prescindir deles próprios. No lugar, formou-se uma muito mais complexa, na qual conviviam os antigos órgãos do Estado, os novos que vinham do partido e ainda outros, oriundos da própria figura do líder único. Uma estrutura caótica, com interpenetrações, conflitos e alianças e cuja contradição central, ainda que não a única, era a existente entre o partido e o Estado.

Um dos pontos de maior atrito foi o relacionado ao aparato de segurança, policial e militar. Tradicionalmente, as forças do Estado são as responsáveis pelo monopólio do uso da força, tanto interna como externamente. Os partidos fascistas, contudo, criaram forças paramilitares - como as Sturmabteilung (SA) e as Schutzstaffel (SS) alemãs e a Milizia Volontaria per la Sicurezza Nazionale (MVSN) italiana - para a ação política e, após a tomada do poder, abriu-se imediatamente a questão de como integrá-las na nova ordem, especialmente frente ao poder da polícia e das Forças Armadas. Uma questão, na verdade, nunca resolvida e que permeou a trajetória das duas ditaduras até o final.

Esse artigo pretende trabalhar essa questão, mas com um foco no problema da polícia e da justiça. O conflito dos milicianos com as Forças Armadas está totalmente relacionado com a questão da polícia e do sistema judicial, o que tornará imprescindível mencioná-lo, mas tem particularidades que demandam um artigo específico, o qual dialogará com o presente. Além disso, a historiografia que aborda o tema tradicionalmente dirige o seu foco justamente à relação entre os militares e as milícias, deixando de lado a questão da polícia. Essa lacuna é dificilmente justificável, até porque uma investigação do relacionamento da polícia com as milícias pode nos ajudar a entender melhor o funcionamento dos Estados fascistas ou daqueles onde os fascistas participaram do bloco de poder dominante, como na Espanha.

Para dar conta dessa tarefa, a estrutura do artigo será bastante tradicional. Na primeira parte, o foco será na Itália Fascista e na relação das milícias com policiais e operadores do sistema judiciário, enquanto a segunda parte fará o mesmo com relação à Alemanha nazista. $\mathrm{Na}$ parte final, farei uma comparação desses dois casos com outros sistemas políticos e policiais da época, de forma a pensar possíveis padrões gerais de relacionamento entre Estados, partidos e polícias. Para tanto, os "casos de controle" que selecionei foram três: o Japão Imperial, o Estado Novo de Getúlio Vargas e a ditadura de Francisco Franco. Ao utilizar esses "casos de controle", poderei avançar também outra das hipóteses do artigo, ou seja, que há uma relação inversa entre a institucionalização de uma nova ordem e a sobrevivência do autoritarismo nos sistemas judicial e policial no pós-ditadura. 


\section{Milícias e polícia: Conflitos e alianças no fascismo italiano}

Como bem indicado pelo historiador Emilio Gentile (2002), o fascismo italiano tinha uma perspectiva totalitária e o Partito Nazionale Fascista (PNF) se considerava a ponta de lança para a transformação do Estado e da sociedade nesse sentido. Sem uma perspectiva ou ambição totalitária, na verdade, a própria definição de fascismo fica incompleta. $\mathrm{O}$ trabalho de Gentile é importante para redimensionar o papel da ideologia totalitária e do Partido Fascista dentro do fascismo italiano. Fica o fato, contudo, que a perspectiva totalitária nunca foi dominante e que o Partido Fascista, apesar dos seus esforços, ficou num papel secundário na estrutura de poder do regime.

O fato historicamente verificável é que, durante o regime, a perspectiva autoritária superou a totalitária e o Estado foi capaz de sobreviver às investidas do partido, mas que esse jamais foi completamente anulado, o que gerou tensões e disputas contínuas. As lutas entre o Exército, a polícia e a Milícia são indícios justamente de que a tensão entre as duas perspectivas foi uma constante.

Em linhas gerais, portanto, o Partito Nazionale Fascista foi sublimado pelo Estado e seu projeto de nacionalização das massas ficou incompleto. Isso se deu, em boa medida, pela sua incapacidade em disciplinar e controlar as tendências regionalistas, nas províncias. Isolado e tendo perdido sua capacidade de decisão, o partido se tornou cada vez mais uma instância burocrática e formal de poder, de pouca importância real (CORNER, 2012).

Ainda mais importante para explicar o enfraquecimento do PNF foi a maneira como se construiu o bloco de poder que levou o fascismo ao comando do Estado. Desde 1922, os fascistas compartilharam o poder com as elites tradicionais - as Forças Armadas, a Igreja, os grandes empresários e proprietários de terra, a burocracia tradicional e a Monarquia -, sendo capazes, na maior parte do tempo, dominá-las. Nunca conseguiram, contudo, anular por completo as outras forças. Esse bloco de poder só se rompeu em 1943, quando Mussolini foi derrubado do poder pelos seus aliados conservadores e o regime fascista se converteu na Repubblica Sociale Italiana (BERTONHA, 2008).

Em outras palavras, no caso italiano o controle fascista sobre o Estado foi menos abrangente e o regime jamais conseguiu eliminar certas fontes de poder paralelo, como a Monarquia e a Igreja. Do mesmo modo, o grau de fusão entre partido e Estado foi menor e o próprio Mussolini exercia uma autoridade paralela, até certo ponto, de ambos. Até por causa disso, os choques entre partido e Estado foram mais intensos do que na Alemanha 
e continuaram por todo o período. Em linhas gerais, pode-se concluir que o Estado e a figura pessoal de Mussolini acabaram por ter mais peso do que o partido na estrutura de poder italiana (ADINOLFI, 2012; MUSIEDLAK, 2012).

Isso se refletiu na questão dos esquadristas e milicianos dentro do Partido. Os esquadristas haviam sido fundamentais para a conquista do poder, ao menos enquanto arma de intimidação, propaganda e socialização. Mesmo assim, eram um perigo potencial, já que sua independência e até indisciplina frente ao partido gerava problemas para a sua liderança. Outra dificuldade era que, dentro do bloco de poder de Mussolini, havia um acordo tácito com o Exército e outras forças do Estado pelo qual essas forças continuariam a ter o monopólio da força. Esse acordo implicava anular quaisquer ambições dos milicianos de substituírem os militares e policiais como os que exerciam a violência legítima dentro do regime. A resposta para essa questão foi a incorporação das forças esquadristas dentro da MVSN, criada em 1923, e a incorporação desta ao aparelho do Estado, no ano seguinte (REICHARDT, 2009).

Mesmo com a incorporação oficial ao Estado, a milícia fascista continuava a ser, em essência, oriunda e controlada pelo partido e suas centenas de legiões milicianas não eram uma força negligenciável. Sua subordinação ao Exército e à polícia representou o seu enfraquecimento enquanto arma política, mas não o fim das tensões entre as forças nos anos a seguir.

Com efeito, a milícia criou, durante o ventênio fascista, várias unidades militares, que iam desde divisões completas de infantaria (que lutaram nas Guerras da Etiópia e da Espanha e na Segunda Guerra Mundial) aos batalhões regulares incorporados às divisões do Exército e os de elite (os chamados Batalhões M, de Mussolini). Unidades da milícia também se tornaram responsáveis pela defesa antiaérea e pela vigilância de infraestruturas chave. Elas também se tornaram uma força paramilitar interna, com funções semelhantes a da polícia.

No caso italiano, espanta, na realidade, como bem indicado por Camilla Poesio (2010), o pequeno número de estudos a respeito da MVSN. Com a exceção da produção coeva ou memorialística e de alguns poucos esboços a respeito da sua função política os trabalhos disponíveis sobre as forças paramilitares do PNF são realmente limitados. E há ainda menos material sobre a crucial questão do seu papel repressivo dentro do regime. Esses estudos, além disso, não respondem a contento a uma pergunta simples: quem 
controlava a polícia? E quem, no Estado fascista, exercia o papel principal no controle da dissidência interna e na manutenção da ordem? O Estado ou o partido?

O comando das forças policiais é crucial em qualquer Estado e ainda mais em um Estado autoritário. No caso italiano, as alterações na estrutura da polícia são indicativas do modelo de Estado que se construiu e do receio de Mussolini de dar o controle da polícia a algum membro do Partido Fascista, o qual, potencialmente, poderia utilizá-la para tentar a conquista do poder. A tática de dividir para governar e o necessário equilíbrio entre o fascismo e as forças tradicionais deu o tom ao regime também na hora de organizar e comandar a polícia.

Já em 1923, institucionalizou-se a absorção da MVSN dentro do Estado e decretouse o fim do Corpo della Regia Guardia per la Pubblica Sicurezza, o que deixou os carabinieri como a única força policial militarizada da Itália. Nos anos seguintes, entre 1924 e 1926, sob o comando de Francesco Crispo Moncada, o sistema se sofisticou e se formou o Servizio Speciale di Investigazione Politica, embrião da Organizzazione per la Vigilanza e la Repressione dell' Antifascismo (OVRA). Moncada, contudo, foi acusado de não ter sido capaz de impedir os vários atentados à vida de Mussolini nesses três anos e foi removido do cargo em 1926 (FUCCl, 1985).

A partir desse ano, o comando da polícia passou para uma figura chave do regime, Arturo Bocchini (1880-1940) e sua autonomia foi reafirmada, dentro do Ministério do Interior (SAVELLA, 1996). Bocchini centralizou a polícia sob o seu comando (ficando fora de sua alçada apenas a MVSN e os carabinieri). A partir de 1927, com a criação da OVRA, unidade especial de repressão ao antifascismo, sua capacidade de ação e influência aumentaram ainda mais. A OVRA interceptava a correspondência e as chamadas telefônicas, infiltrava agentes em organizações potencialmente subversivas (dentro e fora da Itália) e mantinha um cuidadoso sistema de arquivos, de delatores e vigilantes anônimos para enquadrar e vigiar a população. Mesmo com um pequeno número de homens, a OVRA era o órgão coordenador de todas as forças de segurança para a vigilância, a coleta de informações e a repressão dentro e fora da Itália.

Ao final da década de 1930, por fim, a OVRA começou a manter um contato íntimo com a SS e a SD nazistas, reforçando ainda mais sua rede de vigilância fora da Itália, mas mantendo sua independência. A polícia política italiana nunca chegou aos níveis de brutalidade da alemã, mas, mesmo assim, era um aparato de controle impressionante. A violência política era, com 
efeito, um elemento fundamental para a sobrevivência do regime (EBNER, 2010) e a sua polícia era rápida e eficiente ao lidar com a dissidência e os insatisfeitos.

A proeminência da polícia fica evidente quando recordamos que a última vez em que os milicianos foram utilizados para manter a ordem pública foi em junho de 1924, durante o caso Matteoti (CROCIANI; BATTISTELLI, 2011). Depois disso, por vinte anos, a essência da repressão ficou por conta da polícia e do aparato judicial, o qual, mesmo sob controle fascista e com representação da MVSN em algumas instâncias, continuou a ser um órgão de Estado.

Isso não significa afirmar que a magistratura e o sistema judicial ficaram imunes à ideologia fascista. O regime impregnou o sistema judiciário da sua ideologia (como o corporativismo e, a partir de 1938, o racismo antissemita) e de seus métodos, incluindo, por exemplo, a novidade do confino (o exílio interno). Também controlou os magistrados e, progressivamente, os colocou em posição cada vez mais subordinada (BEAULIEU, 2006). O regime também criou um tribunal para julgar especificadamente os crimes de antifascismo, o Tribunale Speciale per la Difesa dello Stato. Mesmo dentro desse Tribunal, contudo, havia uma predominância de militares, sendo os milicianos minoria ou em posição subordinada (VINCI, 2016).

Em resumo, o sistema judicial italiano foi controlado e influenciado pelo regime e instâncias judiciais fascistas foram criadas, mas o sistema judicial permaneceu, em essência, dentro do Estado e não foi posto sob o comando direto do partido.

Voltando ao tema da polícia, até mesmo em termos locais o seu poder frente à milícia foi continuamente reafirmado. Os Uffici Investigativi da Milícia, instalados em cada província, tinham poder de investigação e certa independência, mas o poder coercitivo estava nas mãos dos prefetti (representantes do Ministério do Interior) e dos comissários de polícia locais. Apenas eles, igualmente, podiam indicar pessoas para o confino, apesar da Milícia ter um papel especial na sua administração (POESIO, 2011). As outras forças milicianas só podiam exercer sua função repressiva com o beneplácito da polícia e mesmo a Milizia Confinaria, uma força da MVSN que vigiava as fronteiras italianas, estava, em última instância, subordinada à polícia. Como um todo, ela pode ter se tornado fascista, mas não um órgão sob o controle do Partido Fascista (CORNER, 2012).

Com a morte de Bocchini em 1940, assumiu o comando Carmine Senise, com o apoio de setores do PNF que imaginavam, assim, poder controlar as forças policiais. Isso, contudo, não ocorreu. Senise procurou aumentar ainda mais a autonomia e a força da polícia, não apenas frente ao partido, mas também frente ao regime em si e ao próprio 
Mussolini. Até por isso, ele era visto com desconfiança pelos aliados nazistas da Itália e foi demitido pelo Duce em 14 de abril de 1943, numa tentativa de retomar o controle do aparato policial (CANALI, 2018). Após a guerra, ele se apresentou como um fiel servidor do Estado e da pátria que, desde 1940, percebeu que o fascismo iria ruir e se preparou para tanto, numa perspectiva quase antifascista (SENISE, 1946). Isso não passou, contudo, de um esforço de normatização da polícia, mas que não se sustenta.

Com efeito, a hipótese de uma polícia quase despolitizada, entidade autônoma do Estado, é pouco crível, dada a sua evidente e ativa participação no sustento do regime por décadas. As várias forças de polícia, da milícia, do partido e do Estado eram independentes e rivais, mas trabalharam todas, por décadas, de forma complementar, para a manutenção da ordem fascista na Itália. O que é fica claro é que, sob o comando de Senise, a polícia procurou se afastar do regime e se aproximou das forças conservadoras que, aos poucos, se desvinculavam de Mussolini e do regime, até pelo medo de uma revolta popular na Itália.

Com a criação da Repubblica Sociale Italiana, o relacionamento entre soldados, policiais e milicianos voltou a se tornar um problema. Com o colapso do fascismo, cinquenta e seis divisões do antigo Exército italiano foram desarmadas pelos alemães e imediatamente começou-se a discutir o caráter das novas forças militares e policiais a serem construídas. O reconstruído Partido Fascista procurou garantir que, a partir de agora, as forças militares e da polícia estivessem sob seu controle direto. A ideia inicial era que fossem reconstruídas as unidades da milícia e, a partir dela, surgissem as forças armadas da República. Era uma forma de se destacar do Exército e continuar a tradição da MVSN. O comandante da Opera Nazionale Balila, Renato Ricci, deveria assumir o comando e ele chegou a prever, em 30 de setembro de 1943, a criação de divisões inteiras de milicianos aos moldes das Waffen SS.

O projeto, com o apoio de Pavolini, iria fazer surgir um Exército político, fascista, mas, justamente por isso, o projeto enfrentou resistências. Os antigos membros da milícia temiam perder protagonismo frente aos jovens e os militares leais a Mussolini, como Graziani e Canevari, queriam um novo Exército, fiel ao Estado e não ao partido. O próprio Mussolini parece ter temido os efeitos políticos de tal proposta e os alemães também preferiam tropas regulares, mais eficientes, do que as milicianas.

Ao final, decidiu-se pela criação de forças armadas regulares (num total de quatro divisões, mais forças aéreas e navais e unidades independentes), até para dar a entender que a República era a continuidade do Estado italiano e não era apenas um Estado satélite 
alemão. Muitas delas, como a X MAS, operaram de forma independente do comando fascista, estando sob a dependência direta dos alemães, o que gerou imensos conflitos de competência. Foi também criado um Corpo di Polizia Repubblicano, que absorveu o pessoal civil da polícia no território da nova República e dispunha de unidades para controle de território e combate aos partigiani. Era a quarta força armada da RSI, fortemente fascistizada ideologicamente, mas sob controle militar. Mesmo em um momento desesperador, a luta entre militares e milicianos não diminuía, senão o contrário, e os militares, novamente, venceram o conflito

O novo Partido Fascista Repubblicano conseguiu, contudo, criar uma milícia própria, para fins de controle de território e segurança interna: a Guardia Nazionale Repubblicana (GNR), fundada em novembro de 1943. Ela reunia a antiga MVSN (incluindo os antigos batalhões $\mathrm{M}$ ), os carabinieri que haviam permanecido leais e a antiga Polizia dell'Africa Italiana. Com cerca de 140 mil homens no início de 1944 - mas com diminuição rápida dos efetivos a partir de então, especialmente depois do desarme dos carabinieiri pelos alemães - ela conseguiu manter alguma autonomia frente aos militares, mas sem atingir o objetivo de substituí-los ou de se tornarem a principal força armada da nova Itália (ILARI, 1988).

A incapacidade da GNR em controlar o território e mesmo de manter seus efetivos fez Mussolini, em decreto de 14/8/1944, retirar dela a função de controle do território e a policial e a transformou, ao menos no papel, em uma força de combate, sob comando dos militares. Dois meses depois, ele tentou, aliás, organizar um corpo policial para assumir a função de segurança interna, mas com pouco sucesso. Mesmo assim, é evidente como a GNR foi, na maior parte do tempo, mais uma força de polícia do que uma estritamente militar

O Partito Fascista Repubblicano também organizou as Brigate Nere, unidades especiais sob seu comando direto, para a proteção dos hierarcas fascistas e também para a repressão aos antifascistas. Conforme indicado por Illari (1988) e, especialmente, Gagliani (1999), as Brigate Nere foram o retorno final do fascismo ao esquadrismo e à violência.

Seja na GNR ou nas Brigate Nere, os fascistas encontraram um espaço inédito de independência frente ao Exército e ao Estado, mas sem uma vitória final. Os militares triunfaram novamente frente aos milicianos e as principais forças armadas da RSI eram fascistas, mas não controladas diretamente pelo Partido Fascista.

No caso das forças de polícia, contudo, minha hipótese é que a milícia acabou por triunfar ou, no mínimo, adquirir mais espaço do que nunca. Afinal, as ações policiais - de repressão à dissidência e à guerrilha e de proteção aos líderes fascistas - passaram para 
a competências dos milicianos enquadrados na GNR e nas Brigate Nere, ainda que sob supervisão alemã. Ainda nesse momento, um novo Tribunale Speciale per la Difesa dello Stato foi criado e, apesar de ele continuar a pertencer ao Estado, teve uma maior influência do Partito Fascista Repubblicano do que no período anterior.

Um elemento fundamental para entendermos a questão se refere à segurança pessoal de Mussolini, um tema que desenvolvi em um artigo específico (BERTONHA, 2021). Refletindo o bloco de poder formado pelo fascismo, ele preferiu manter a sua segurança pessoal nas mãos das forças do Estado, e não do Partido Fascista. Nos tempos em que os fascistas lutavam nas ruas pelo poder, esquadristas o protegiam dos inimigos, mas, após assumir o posto de primeiro-ministro, ele foi colocado sobre a proteção de um grupo de vinte homens da polícia. Depois dos atentados contra sua vida nos anos 1920, a sua força de segurança foi reforçada através da criação de uma squadra presidenziale com 500 homens, formada por carabinieri, policiais e camisas negras, mas sob comando de um oficial da polícia (FUCCI, 1985).

Essa decisão teve implicações chave quando do golpe de Estado de 1943. Os golpistas puderam contar com o apoio do Exército, fiel ao rei, do corpo de carabinieri e da polícia, que apoiou a deposição de Mussolini. Carmine Senise estava entre os articuladores do golpe, tanto que Badoglio o restituiu ao comando da polícia em julho de 1943. Foi ele que organizou a prisão de Mussolini e de outros hierarcas fascistas por equipes policiais e, além disso, trouxe reforços policiais para a cidade para, se necessário, enfrentar as milícias do PNF (CANALI, 2018). Fica clara, portanto, a vulnerabilidade de Mussolini por ter confiado em forças do Estado para a sua proteção e como a polícia, apesar de influenciada pelo fascismo, manteve autonomia suficiente para tomar decisões próprias em momentos decisivos.

\section{O caso alemão}

Como indicado acima, os conflitos entre partido e Estado e entre inúmeras organizações e grupos de interesse foram comuns no universo do fascismo. No caso alemão, isso não foi diferente e a historiografia moderna indica com clareza como o regime contrapunha uma liderança única com uma constelação de grupos rivais, oriundos do Estado, do partido e de impérios pessoais. Os órgãos do Nationalsozialistische Deutsche Arbeiterpartei (NSDAP) se sobrepunham aos do Estado, se articulavam com eles ou disputavam entre si, numa constelação de poder que alguns chegaram a chamar de quase feudal. 
Paul Corner (2012), contudo, chama a atenção sobre como, apesar dessas disputas intensas, a Alemanha nazista foi capaz de controlar os interesses locais e disciplinar a máquina do Estado e a do partido de forma muito mais eficiente do que na Itália. Os Gauleiter nazistas eram tão ambiciosos como os ras italianos e tinham mais poder do que os últimos. Na Alemanha, contudo, a presença de uma polícia política com base no Partido Nazista (a SS) e um poder mais centralizado em Hitler teriam permitido que o controle do centro sobre a periferia fosse mais efetivo do que na Itália.

Isso parece uma contradição e a historiografia oscila entre privilegiar um ou outro lado: caos apesar dos esforços de comando, ou centralização, mas dentro de uma essência caótica. Dado o fato que, apesar de tudo, o nazismo conseguiu se manter no poder até o final e colocar em prática os seus programas, é provável que a segunda opção seja a mais correta. Isso se deu, provavelmente, pela maneira pela qual o nazismo chegou ao poder, sendo capaz de, com alguma rapidez, colocar para escanteio as forças tradicionais militares, burocracia estatal, partidos conservadores etc. - que o haviam apoiado. $\mathrm{O}$ fato de a Monarquia ter sido abolida na Alemanha em 1918 também evitou conflitos como na Itália.

Além da questão dos equilíbrios de poder, contou também, para explicar a especificidade alemã, a própria concepção nazista de Estado. Como bem recuperado por Moraes (2007), fascismo e nazismo compartilhavam a perspectiva de um Estado autoritário com perspectivas totalitárias, mas divergiam na visão de como o Estado deveria se relacionar com o partido e na concepção mesma de Estado. Carl Schmidt foi um intelectual fundamental nessa construção ideológica e constitucional do novo regime e já nas obras clássicas que estudaram o tema - como Fraenkel, Neumann e Arendt - a questão aparece. A dualidade Estado/partido foi evidenciada também na historiografia mais recente.

Se, como visto, o fascismo italiano tendia a anular o partido no Estado, a perspectiva nazista era a de que o Estado era um instrumento a serviço da ideologia, com o partido tendo precedência e servindo, inclusive, para a transformação do Estado. O princípio da autoridade também diminuía a distância entre partido e Estado e reforçava a união entre ambos.

Na Alemanha, uma lei promulgada em 1933 - Gesetz zur Sicherung der Einheit von Partei und Staat - já indicava a proeminência do partido sobre o Estado e, a partir de então, o NSDAP foi assumindo cada vez mais proeminência. No ano seguinte, os poderes especiais obtidos por Hitler permitiram a promulgação do conjunto de leis conhecido por Gleichschaltung. Através dele, os nazistas conseguiram a eliminação dos estados federais, o expurgo dos funcionários públicos e um grau de controle do Estado maior do que na Itália. Basta recordar, 
pensando em termos simbólicos, como a bandeira tricolore italiana nunca foi substituída pela bandeira do Partido Fascista, enquanto a nazista eliminou a bandeira alemã em 1935.

Na Alemanha, dessa forma, houve uma alteração do equilíbrio de forças em direção ao partido desde a consolidação do regime nazista e, especialmente, na fase final da Segunda Guerra Mundial. Isso aconteceu em todas as esferas de ação pública, mas com especial força no sistema de segurança, entre os militares, os juízes e os policiais.

No caso dos militares, havia uma intensa rivalidade entre eles e a milícia do partido, a SA e, mais tarde, a SS. Os militares venceram a disputa com a SA, praticamente destruída na "Noite das Longas Facas" de 1934, mas perderam, em termos políticos, sua disputa com SS. Desde 1934, a posição dos militares foi sendo limitada e controlada. Eles continuaram comandando a essência das forças militares, reunidas na Wehrmacht, mas Hitler foi capaz de anular a sua autonomia. O controle do Partido Nazista e da SS sobre o aparato militar aumentou ainda mais depois da tentativa de golpe militar em 1944. Os oficiais comandavam, apesar da existência das divisões da Waffen-SS, a maior parte do poder militar alemão, mas perderam a precedência política e acabaram subordinados dentro do aparelho do Estado.

Em outras palavras, como indicado por Reichardt (2009), tanto a MVSN italiana quanto as SA alemã tinham imensa autonomia no início, gerando disputas que tanto Mussolini como Hitler tiveram que resolver. Mussolini optou por colocá-las sob o controle do Estado, enquanto Hitler as eliminou e criou outra força, a SS, para agir, independente tanto do partido como do Estado. Uma diferença chave, que refletia as diferentes perspectivas dos dois modelos de fascismo e que teve implicações políticas de monta na hora de uma crise de legitimidade.

Na polícia, o mesmo processo aconteceu, novamente tendo como protagonista a SS. O primeiro problema foi domesticar a SA, a qual, com a chegada de Hitler ao poder, quis assumir funções policiais nas cidades e campos alemães. A primeira tentativa de controle veio com a criação, já em 1933, da Hilfspolizei, que incorporava os membros da milícia do partido em unidades policiais. A experiência, contudo, durou pouco, até porque a SA não aceitou ser comandada pela polícia, e o movimento foi, a partir de 1934, na direção contrária: as forças policiais foram sendo retiradas dos órgãos de Estado que sempre as haviam controlado e transferidas para o comando da SS e do NSDAP, sendo as SA colocadas para escanteio. 
Até a chegada do nazismo ao poder, as funções policiais na Alemanha eram exercidas basicamente em nível local e regional, por estados e municípios que dispunham de policiais uniformizados e civis para o controle da população e repressão à criminalidade. Obviamente, os maiores entes federados - como a Baviera e, acima de todos, a Prússia tinham forças policiais mais numerosas e bem organizadas. O Ministério do Interior tinha pouco controle sobre elas, tanto que, em 1933, a nomeação de um nazista, Wilhelm Frick, para o seu comando causou pouca controvérsia, pois seus poderes eram pequenos.

Logo ao chegar ao poder, o nazismo promoveu, como já mencionado, uma centralização política na Alemanha, e a polícia não foi exceção: o Ministério do Interior passou a comandar a polícia, agora organizada nacionalmente. Ao mesmo tempo, a divisão de poderes e atribuições entre os líderes nazistas prosseguiu, limitando o poder do Ministério do Interior: Himmler assumiu o comando das forças policiais da Baviera e era, desde 1931, chefe do serviço de segurança do partido e da SS, a Sicherheitsdienst (SD). Ao mesmo tempo, Hermann Göring, ministro do interior da Prússia, manteve as forças policiais da Prússia sob seu comando particular e também criou uma polícia política específica, a Geheime Staastspolizei (Gestapo), em 1933, cujas atribuições foram depois estendidas a todo o território alemão ou ocupado.

Com o tempo, contudo, o poder policial foi se concentrando nas mãos da SS, de Himmler e do seu colaborador chave, Reinhard Heydrich, com a derrota dos seus rivais nazistas e também dos conservadores que tentavam reter o controle da polícia através do Ministério do Interior. Eles comandavam a SD e todas as forças policiais alemãs - como a Gestapo e a polícia criminal, Kriminalpolizei (Kripo) - foram gravitando para o seu controle. Em 1936, Himmler foi nomeado chefe de toda a polícia alemã e, apesar de os conflitos de competências entre as agências e grupos continuarem, o sistema se tornou mais centralizado.

Quase sempre, a SD atuava como uma agência de espionagem externa e interna, enquanto a Gestapo e a Kripo eram as que executavam as prisões. Mesmo assim, para evitar atritos, em 1936 a polícia, sob o comando geral de Himmler, foi dividida em Ordnungpolizei (Orpo), e Sicherheitspolizei (Sipo). A primeira era composta pelos antigos corpos de polícia urbanos e rurais. Já a Sipo reunia a Kripo e a Gestapo e foi colocada sob o comando de Reinhard Heydrich, que também comandava a SD. Heydrich tentou deixar mais claras as funções e prerrogativas de cada corpo mas, em 1938, a SD recebeu a prerrogativa de agência de inteligência não apenas do partido, mas do Estado, o que a colocou em rota de colisão com a espionagem militar, a Abwehr, e gerou ainda mais conflitos. 
Em 1939, finalmente, surgiu a Reichssicherheitshauptamt (RSHA), que reunia a Sipo e a SD. A SS também comandava a Orpo e, com a derrota do golpe militar de 1944, a Abwehr foi incorporada à SD (BROWDER, 1996, 2015). Além disso, com a exceção de algumas divisões de elite, não se pode esquecer que a maioria das divisões da Waffen-SS, apesar de organizadas em um formato militar, eram essencialmente forças de polícia, com tarefas de combate à guerrilha e manutenção da ordem no espaço dominando pelos alemães.

Todas essas forças tinham identidades de corpo e algum grau de independência e é evidente que houve limites para a sua nazificação (BROSZAT, 1981), mas todas foram permeadas, em maior ou menor grau, pela ideologia nazista. Isso tanto é verdade que unidades da polícia cometeram massacres na frente oriental durante a guerra e tanto o famoso batalhão 101 da polícia estudado por Christopher Browning (2017) como a $4^{\mathrm{a}}$ Divisão das Waffen-SS Polizei, eram, na verdade, unidades da Orpo.

Para nosso argumento, o importante a recordar é que, nos anos 1940, o sistema policial nazista havia atingido um alto grau de capilaridade na Alemanha e nos territórios ocupados e que ele foi eficiente na repressão aos dissidentes e no combate aos inimigos do Reich. O comando geral da polícia acabou, dessa forma, ficando com o NSDAP ou, para ser mais preciso, com a SS.

O mesmo pode ser dito do sistema judicial. Toda e qualquer independência foi eliminada, de forma ainda mais acentuada do que na Itália. Os juristas e operadores do Direito foram agrupados em uma associação e juristas como Carl Schmitt estavam, já em 1933, militando pela nazificação total do sistema judicial.

O sistema oficial, estatal, continuou a existir, convertido à ideologia nazista e seguindo métodos e sistemas diferentes do período anterior. ${ }^{1}$ Já em 1933, surgiram os Sondergerichte, tribunais especiais para julgar crimes políticos, os quais se espalharam pela Alemanha e, depois, pelos territórios ocupados. Em 1934, foi criado o Volksgerichtshof (Tribunal do Povo), o qual abandonou toda e qualquer formalidade jurídica em favor de uma repressão aberta e intensa aos inimigos políticos do nazismo. Se o sistema judicial fascista condenou aproximadamente 120 italianos à morte em vinte anos, os tribunais nazistas multiplicaram esse número por cem, sem contar os territórios ocupados.

\footnotetext{
${ }^{1}$ Para uma discussão sobre a natureza do Estado nazista, especialmente no campo do Direito, ver Meierhenrich (2018). O autor recupera a obra de Ernest Fraenkel e sua polarização com a de Franz Neumann e atualiza o debate, defendendo a proposta de Fraenkel do Terceiro Reich como um Estado Dual: normativo para a população em geral e prerrogativo para os inimigos do regime.
} 
Além disso, surgiram instituições judiciais fora do Estado, ainda que não sob o controle do partido. A Haumptamt SS-Gericht, por exemplo, era o sistema legal da SS, o único no qual seus membros podiam ser julgados, com a exceção de tribunais militares. $O$ historiador Karl Dietrich Bracher (1970) ressalta como a sua criação retirava a SS de todo e qualquer controle civil ou do Estado. Salvo engano, nunca houve um tribunal com poderes semelhantes dentro da MVSN italiana. Quando o historiador Lutz Klinkhammer (2010) afirmou que o sistema nazista era muito mais radical do que o italiano, ele resume exemplarmente a questão chave: o nazismo revolucionou o Estado de forma muito mais completa do que o fascismo.

A preservação de boa parte do sistema policial e judicial anterior foi, contudo, chave para que o Estado policial nazista se mantivesse. Como indicado por Robert Gellately (2002), a Gestapo e outros órgãos policiais propriamente políticos eram pequenos demais para cobrir toda a Alemanha, demandando a colaboração da população, em forma de denúncias e vigilância do vizinho, para o exercício do poder. Isso está correto, mas Richard Evans (2016) também ressalta algo ainda mais importante: a Gestapo era apenas a ponta do sistema policial nazi, podendo convocar rapidamente outras forças para apoio em caso de necessidade e confiando no sistema judicial tradicional para processar e punir a maioria dos possíveis inimigos do Estado. Outros agentes, como os inspetores de quarteirão ou a juventude hitlerista, amplificavam e se somavam às tradicionais para tornar o sistema ainda mais radicado no território. Dessa forma, considerar que o povo alemão vivia sob a dominação de um poder repressivo demiúrgico seria errôneo, mas imaginar o seu oposto também seria um excesso.

Isso se refletiu na crucial questão da proteção pessoal de Hitler. Desde 1923, ele foi protegido por forças milicianas nazistas, não diretamente subordinadas ao NSDAP, como as Stoßtrupp-Hitler e as várias unidade de escolta da SS, como a Leibstandarte Adolf Hitler, a Führerbegleitkommando (FBK) e a Reichssicherheitsdienst (RSD). Em essência, Hitler era protegido por soldados da SS e não por forças da polícia ou do Exército.

Isso tinha, evidentemente, um efeito político fundamental. Com a segurança de Hitler nas mãos da SS, quaisquer tentativas de removê-lo do poder implicavam ou na traição da SS ou da sua derrota por forças mais poderosas, do Exército e da polícia, o que seria trabalhoso e complicado. Dessa forma, o bloco de poder de Hitler se sustentou melhor do que o de Mussolini porque as suas partes constituintes tiveram a sua autonomia anulada com eficiência muito maior do que na Itália. Contou também, contudo, o fato de Hitler ser 
protegido e guardado por forças ideologicamente comprometidas, o que tornava muito mais difícil a tomada do poder, o que levou a Alemanha a continuar a guerra até o final, em 1945.

\section{Casos de controle: Brasil, Espanha e Japão}

A questão da polícia é fundamental quando pensamos na capacidade dos regimes fascistas em permanecer no poder, como indicado pelos casos de Hitler e de Mussolini. Ao mesmo tempo, contudo, pensar no problema da polícia em outros regimes, especialmente os autoritários, é uma excelente ferramenta para esclarecer a relação entre partido e Estado nos fascismos e a sua importância dentro de uma perspectiva totalitária de poder.

Em ditaduras militares mais "simples", como várias das latino-americanas dos anos 1930, normalmente a polícia estava diretamente subordinada ao Estado e aos militares, mas ela, quase sempre, tinha voz própria na ditadura. Já no caso de uma ditadura civil com suporte militar, a configuração é diferente, como na ditadura varguista. Ela era mantida pelos militares, sem um partido único que disputasse prerrogativas com o Estado. $O$ autoritarismo era a tônica, e quaisquer perspectivas ou acenos totalitários foram descartados de imediato. A relação da polícia com a nova ordem reflete isso. O poder de polícia, sempre importante numa sociedade desigual como a brasileira, se tornou crucial dentro do projeto de poder do Estado Novo, entre 1937 e 1945.

Durante esse período, não foi criada uma polícia específica do regime, mas foi potencializada a polícia política que já existia, tanto em termos de recursos e poderes, como na perspectiva centralizadora e na radicalização ideológica, especialmente no tocante ao anticomunismo. Em todos os estados, a polícia foi depurada de elementos inconvenientes e se sofisticou já a partir de 1930, agindo com mais violência e de forma mais ampla.

Pela sua localização, era a do Distrito Federal a mais importante, já que agia na capital do país e coordenava as ações nos estados - agindo como uma verdadeira Polícia Federal - e até mesmo no exterior. Não espanta que, já em 1933, Vargas a tenha colocado sob o comando direto do Ministério do Interior e da Presidência, mas, em última instância, sob o seu próprio. Em toda a era Vargas, a polícia tinha, na realidade, uma autonomia quase completa, obedecendo apenas ao presidente (CANCELLI, 1994).

Sob o comando de Batista Luzardo, João Alberto e, depois, Filinto Muller, a polícia do DF agia como milícia pretoriana do regime, especialmente com a sua temida Polícia Especial. Se, nos estados, a estrutura da polícia era limitada, no Rio de Janeiro ela tinha 
verbas, pessoal e recursos para agir com muito mais eficiência (CANCELLI, 1994). A Delegacia Especial de Segurança Pública e Social, a polícia política propriamente dita, era apenas parte do corpo policial, mas todo ele estava às ordens do "Estado Novo". Uma prova disso é que a DESPS tinha um número muito limitado de agentes e uma estrutura reduzida (CANCELLI, 1994). No entanto, assim como acontecia com a Gestapo ou a OVRA, essa estrutura podia ser rapidamente amplificada se necessário e podia contar com o resto da estrutura policial como backup. Isso explica porque ela podia ser reduzida tanto no Distrito Federal como, especialmente, nos estados e, mesmo assim, agir com eficiência para controlar a sociedade. Ainda assim, a polícia brasileira nunca teve a capilaridade dos sistemas policiais fascistas e nem estabeleceu padrões de ação próximos ao terror dos Estados totalitários.

O sistema legal também foi alterado para dar vez a uma nova ordem. O código penal de 1890 foi sendo progressivamente abandonado até a substituição completa em 1942. Em 1936, foi criado o Tribunal de Segurança Nacional (TSN), o qual agia nas margens da lei (tanto que era subordinado ao Executivo e não ao Judiciário), mas sem romper completamente com o código legal. Isso indica os limites do Estado Novo, pois o TSN não se compara, por exemplo, com os tribunais de exceção nazistas, onde o rompimento com a ordem legal era muito mais evidente (ROSENFIELD, 2021, especialmente p. 293-323).

Com seu regime e sua segurança pessoal nas mãos dos militares e da polícia, Vargas não teve meios de resistir quando essas forças mudaram de lado e decidiram removê-lo do poder em 1945. Ao mesmo tempo, a independência relativa dos militares, da polícia e do poder judiciário no Estado Novo permitiu que aspectos da sua cultura e as instituições e mentalidades criadas naquele regime acabassem sobrevivendo para influenciar a história do Brasil nos anos e décadas a seguir.

No caso de Franco, vale mencionar o artigo de Jonathan Dunnage (2006) comparando os sistemas policiais da Alemanha Nazista, da Itália Fascista e da Espanha de Franco. Suas conclusões se assemelham as minhas, ou seja, que, no caso alemão, o partido e a milícia assumiram o comando da estrutura policial e repressiva, enquanto, no italiano, houve mais uma reorganização e redimensionamento da polícia e da Justiça do que uma mudança radical. Ele não aborda diretamente o tema das relações entre Estado e partido como fator explicativo, mas ela está implícita.

No caso espanhol, sempre seguindo Dunnage, as milícias falangistas e carlistas foram anuladas politicamente já antes do fim da guerra civil e a Falange não exerceu o 
papel de partido único, no sentido fascista do termo, da ditadura de Franco. Não espantosamente, para um regime baseado no poder do Exército, o poder de vigiar e punir foi concentrado nas mãos dos militares, através de tribunais militares e do controle, por eles, dos corpos de polícia, como a Guardia Civil. A parte esse maior controle e um grande aumento das atividades de vigilância política da população, a polícia continuou, em termos de instituições, essencialmente a mesma.

Já o poder das cortes foi reduzido em favor dos tribunais militares, nos quais as garantias judiciais básicas, como o direito de defesa, foram seriamente reduzidas e que assumiram poderes para julgar inclusive crimes comuns. O regime também criou uma corte especial, com juízes nomeados diretamente pelo governo, e purgou o sistema judicial remanescente de quaisquer potenciais inimigos. O sistema judicial, assim, não foi fascistizado, como teria sido sob o domínio da Falange, mas foi completamente subordinado aos desígnios do regime, especialmente nos anos 1930 e 1940. Nas décadas a seguir, houve uma maior institucionalização e o sistema judicial civil aumentou o seu protagonismo, mas depurado e controlado pelo regime. Como aconteceu no Brasil, isso permitiu a sobrevivência de uma cultura autoritária mesmo após a redemocratização, nos anos 1980.

Um caso diferente foi o do Japão, que tinha uma polícia política própria, a Kempeitai. Fundada em 1881 como a polícia militar do Exército japonês, suas funções foram se expandindo com o passar do tempo. Ela agia como uma polícia militar padrão no meio castrense, executava tarefas de vigilância e controle nos territórios ocupados pelo Império (muitas vezes, recrutando auxiliares nativos) e, no Japão, era responsável pela manutenção da ordem pública, especialmente em termos políticos. Ela também agia como agência de espionagem no exterior, administrava campos de prisioneiros e laboratórios de pesquisa científica em guerra biológica ou química. Não espanta que ela tenha tido ligações não apenas com as agências de espionagem militar italianas e alemãs (como o Servizio Informazioni Militari e a Abwehr),como também com as polícias políticas, como a SS e a MVSN. Outras forças de segurança - como a tokkeitai, da Marinha ou a civil tokkõ - também atuavam nessas funções, mas a Kempeitai era a mais importante.

É relevante observar onde se situava a Kempeitai em termos de organização e hierarquia. Ela estava nominalmente subordinada aos ministérios civis em território japonês e ao Ministério da Guerra no exterior, mas sua filiação básica era ao Exército, ou, em outras palavras, ao Estado. Apesar de algumas sugestões que pessoas e grupos da extremadireita japonesa estavam presentes com especial força entre os kenpei (DEACON, 1990), 
a força nunca serviu a um partido, mas ao Estado. Em 1945, ela foi dissolvida pelos ocupantes americanos e isso permitiu uma reorganização da polícia no Japão, num sentido mais democrático

\section{Considerações finais}

A relação da polícia, do sistema judicial e das forças armadas com as democracias e as ditaduras é, evidentemente, fundamental para entender a transição entre esses regimes, nos mais diferentes contextos e épocas. No caso dos regimes fascistas, é perceptível como essas forças apoiaram a transição dos regimes liberais italiano e alemão para o fascismo, sendo a discussão maior a relacionada sobre os motivos para isso. As possíveis respostas vão desde questões institucionais, similaridades ideológicas ou mesmo mentalidades semelhantes. Outra questão fundamental é a de como a nova ordem incorporou e redefiniu o papel de militares, juízes e policiais, mantendo as estruturas antigas e/ou as substituindo por novas.

No processo de formação de qualquer ditadura, o sistema judicial e as forças de polícia são impregnadas pela nova ideologia dominante e acontece a depuração e a renovação dos seus membros, sendo esse processo mais suave ou mais intenso conforme o grau de comprometimento deles com a nova ordem. O diferencial das ditaduras com aspirações totalitárias, como as fascistas, é a eliminação ainda mais intensa da independência dessas forças e a criação de instituições policiais e sistemas de julgamento e punição paralelos, normalmente com base no partido.

No caso alemão, o nazismo foi capaz de implementar esse processo com muito mais intensidade, centralizando e disciplinando as forças policiais e o Judiciário e criando uma sólida estrutura paralela, a SS. Na Itália, Mussolini preferiu confiar na fascistização do Estado e as prerrogativas policiais do partido foram extremamente restringidas, sem chegar a serem inexistentes. O mesmo aconteceu na Espanha, onde o poder de polícia da Falange foi efetivo durante a Guerra Civil, mas sob controle militar, para ser depois quase que completamente eliminado em favor das forças do Estado.

A ditadura varguista no Brasil, por sua vez, não criou um partido que pudesse assumir funções policiais e optou por ampliar os poderes das estruturas tradicionais, fundando apenas umas poucas instituições novas, como o Tribunal de Segurança Nacional ou a Polícia Especial de Filinto Muller. Já no Japão, a particularidade maior foi que a polícia 
política já existente há décadas foi assumindo cada vez mais funções, até se tornar uma próxima da Gestapo ou da OVRA em termos de poderes e abrangência, mas sob comando das Forças Armadas.

Após 1945, as estruturas policiais e judiciárias criadas pelos partidos fascistas (ou, no caso japonês, pelo regime militar) estavam tão ligadas às ditaduras que sua eliminação era inevitável, especialmente sob a ocupação americana. Homens ligados à SS, à Gestapo, à OVRA ou à Kempeitai foram incorporados às forças policiais dos seus países depois da guerra (até porque eram especializados na luta contra o comunismo, tarefa essencial dos Estados capitalistas na Guerra Fria) e levaram a elas a cultura política e policial do período anterior. Não obstante, essas instituições cessaram de existir e a quebra de continuidade foi positiva para a redemocratização desses países.

Já no tocante às forças policiais mais tradicionais e ao Judiciário, é conhecido como a depuração do período anterior foi relativamente branda e boa parte da cultura autoritária e de vigilância foi reconstruída posteriormente, ainda que nos termos da Guerra Fria e da redemocratização. A possibilidade de uma continuidade institucional e geracional foi maior nesses casos, com o consequente déficit democrático. O caso italiano, estudado por Jonathan Dunnage (2006), indica isso com clareza: a polícia e o sistema judicial da época de Mussolini, preservados em boa parte pela aura de "simples servidores do Estado", continuaram desconfiando da democracia e prontas a apoiar iniciativas autoritárias. Mesmo assim, o fim da OVRA e dos tribunais fascistas foi um passo essencial para a consolidação do sistema democrático italiano.

A polícia e a Justiça existem e funcionam segundo as normas da sociedade que as abrigam, ao mesmo tempo em que condicionam e influenciam essas sociedades, ao menos até certo ponto. O período entre as duas guerras mundiais foi um de ditaduras e, mais do que isso, de vários tipos e combinações de propostas ditatoriais: de direita e de esquerda, autoritárias e de viés totalitário, castrenses ou não. Elas estabeleceram propostas de organização da polícia e do sistema de punição judicial justamente a partir dessas combinações, cujo estudo e detalhamento pode nos ajudar a compreender melhor as heranças daquele período no posterior e até os dias de hoje. 


\section{Referências}

ADINOLFI, Goffredo. Grande Conselho e governo: elite e decisão política na Itália fascista. In: PINTO, António Costa (Org.). Governar em ditadura: elites e decisão política na era do fascismo. Lisboa: Imprensa de Ciências Sociais, 2012. p. 39-70.

BEAULIEU, Yannick. Magistrature et pouvoir politique en Italie entre 1918-1943: analyse socio-historique des magistrats ordinaires et de leurs relations avec le personnel politique. Florença: European University Institute, 2006.

BERTONHA, João Fábio. Coerção, consenso e resistência num Estado autoritário: o caso da Itália Fascista. Diálogos - Revista do Departamento de História da Universidade Estadual de Maringá, Maringá, v. 12, n. 1, p. 141-163, 2008. Disponível em: https://periodicos.uem.br/ojs/index.php/Dialogos/article/view/38209. Acesso em: 22 nov. 2020.

BERTONHA, João Fábio. Quem guardará os guardiões? A segurança pessoal de Hitler e Mussolini e as relações entre partido e Estado nas ditaduras fascistas. Locus: Revista de História, v. 27, n.1, p. 317-337, 2021.

BRACHER, Karl Dietrich. The German dictatorship: the origins, structure and effects of National Socialism. New York: Praeger Publishers, 1970.

BROSZAT, Martin. The Hitler State: the foundation and development of the internal structure of the Third Reich. London: Longman, 1981.

BROWDER, George C. Hitler's enforcers: the Gestapo and the SS Security Service in the Nazi revolution. Oxford: Oxford University Press, 1996.

BROWDER, George C. Foundations of the Nazi Police State: the formation of Sipo and SD. Lexington: University Press of Kentucky, 2015.

BROWNING, Cristopher R. Ordinary Men: Reserve Police Battalion 101 and the final solution in Poland. New York: Harper Perennial, 2017.

CANALI, Mauro. Carmine Senise. In: Dizionario biografico degli italiani. Roma: Istituto Treccani, 2018. v. 92.

CANCELLI, Elisabeth. O mundo da violência: a polícia na era Vargas. Brasília: Universidade de Brasília, 1994.

CORNER, Paul. Italia fascista: politica e opinione popolare sotto la dittatura. Roma: Carocci, 2012.

CROCIANI, Piero; BATTISTELLI, Pier Paoloi. Le camicie nere, 1933-1945. Gorizia: Goriziana, 2011.

DEACON, Richard. Kempeitai: the Japanese Secret Service then and now. Clarendon: Tuttle Publishing, 1990. 
DUNNAGE, Jonathan. Policing right-wing dictatorships: some preliminary comparisons of Fascist Italy, Nazi Germany and Franco's Spain. Crime, Histoire \& Sociétés / Crime, History \& Societies, v. 10, n. 1, p. 93-122, 2006. https://doi.org/10.4000/chs.200

EBNER, Michael R. Ordinary violence in Mussolini's Italy. Cambridge: Cambridge University Press, 2010.

EVANS, Richard. The Third Reich in History and memory. London: Abacus, 2016.

FUCCI, Franco. Le polizie di Mussolini: la repressione dell'antifascismo nel "ventennio". Milano: Mursia, 1985.

GAGLIANI, Dianella. Brigate Nere: Mussolini e la militarizzazione del Partito Fascista Repubblicano. Torino: Bollati Boringhieri, 1999.

GELLATELY, Robert. Backing Hitler: consent and coercion in Nazi Germany, 1933-1945. Oxford: Oxford University Press, 2002.

GENTILE, Emilio. La via italiana al totalitarismo: II partito e lo Stato nel regime fascista. Roma: Carocci, 2002.

ILARI, Virgilio. II partito armato del fascismo: La Milizia dallo squadrismo alla RSI. In: ILARI, Virgilio; SEMA, Antonio (Org.). Guerra, Esercito e Milizia nella concezione fascista della nazione. Ancona: Nuove Ricerche, 1988. p. 277-414.

KLINKHAMMER, Lutz. Was there a fascist revolution? The function of penal law in Fascist Italy and in Nazi Germany. Journal of Modern Italian Studies, v. 15, n. 3, p. 390-409, 2010. https://doi.org/10.1080/13545711003768592

MEIERHENRICH, Jens. The remnants of the Rechtsstaat: an ethnography of Nazi Law. Oxford: Oxford University Press, 2018.

MORAES, Luís Edmundo de Souza. Sobre a concepção de Estado no Nacional-Socialismo. Revista Universidade Rural, v. 29, n. 1, p. 37-50, 2007.

MUSIEDLAK, Didier. Mussolini, carisma e decisão política. In: PINTO, António Costa (Org.). Governar em ditadura: elites e decisão política na era do fascismo. Lisboa: Imprensa de Ciências Sociais, 2012. p. 25-38.

POESIO, Camilla. Reprimere le idee, abusare del potere: la Milizia e l'instaurazione del regime fascista. Roma: Aracne, 2010.

POESIO, Camilla. II confino fascista. L'arma silenziosa del regime. Roma: Laterza, 2011.

REICHARDT, Sven. Camicie nere, camicie brune: milizie fasciste in Italia e in Germania. Bologna: II Mulino, 2009.

ROSENFIELD, Luís. Revolução conservadora: genealogia do constitucionalismo autoritário brasileiro (1930-1945). Porto Alegre: Edipucrs, 2021. 
SAVELLA, Italo G. Mussolini's "Fouché": Arturo Bocchini, the fascist OVRA, and the Italian police tradition. Rochester: University of Rochester, 1996.

SENISE, Carmine. Quando ero capo della polizia 1940-1943. Roma: Ruffolo, 1946.

VINCI, Stefano. La politica giudiziaria del fascismo italiano nella giurisprudenza del Tribunale Speciale per la difesa dello Stato (1926-1943). Historia et ius - Rivista di storia giuridica dell'età medievale e moderna, Verona, n. 10, p. 01-31, 2016. Disponibile su: http://www.historiaetius.eu/uploads/5/9/4/8/5948821/vinci_10_1.pdf. Accesso effettuato il: 22 nov. 2020 